\title{
Consonancias y disonancias entre lo secular y lo religioso. Un obispo y su legado laico
}

\section{Consonances and dissonances between the secular and the religious. A bishop and his lay legate}

\author{
Gustavo Vega Delgado \\ Universidad Internacional del Ecuador, Ecuador \\ Universidad de Cuenca, Ecuador \\ Universidad Andina Simón Bolívar, Ecuador \\ Johanna Chalén Calderón \\ Universidad Internacional del Ecuador, Ecuador
}

Autor para correspondencia: gvega@uide.edu.ec, jchalen@uide.edu.ec

Fecha de recepción: 20 de octubre de 2017 - Fecha de aceptación: 30 de noviembre de 2017

Resumen: Se aborda en el presente trabajo varias facetas de la vida y obra cuencana de Luis Alberto Luna Tobar, su compromiso con la iglesia de los más vulnerables, su auto transformación como persona y legado como obispo en una ciudad post conservadora. Se desovillan las fuentes conceptuales de su gestión, algunos rostros de su carácter y personalidad, el rol ciudadano, el periodismo de opinión y el activismo ejercido. Los derechos humanos y el compromiso con la Universidad, son quizá los pibotes más relevantes en torno a los cuales giró su quehacer esencial. El enfoque se alimenta de la memoria acumulada, diálogos con el arzobispo emérito de la Cuenca andina. Entrevistas selectivas se incluyen y comentan para clarificar aspectos a la Teología de la Liberación, influencias del Concilio Vaticano II, los Documentos de Medellín y de Puebla, así como nuevos puntos de vista y convergencia, que enrostran iglesia y las tendencias católicas.

Palabras clave: laicismo; seglar; espiritual; religioso; tolerancia; personalidad; derechos humanos; universidad; teología de la liberación

\begin{abstract}
In this paper, different characteristics about bishop Luis Alberto Luna Tobar life, work and his involvement with the more vulnerable people, are discussed. His auto transformation as person and his legacy as a bishop inside a post conservative city, is here treated. We tackle around conceptual sources about his activity, some expressions of his character and personality, his citizenship role, journalist writings and activism. Human rights and his commitment with the university, are perhaps his most relevant axes on his daily activity.

Our vision comes from accumulative memories about him, dialogues and friendship developed with the emeritus archbishop of the andean city of Cuenca in Ecuador.

Selective interviews are included and commented to clarify aspects regarding "Teología de la Liberación", post influences from Vatican Concilium II, Medellin and Puebla Documents, as new points of view and convergence, facing church and catholic new tendencies.
\end{abstract}

Key Words: laicism; secular; spiritual; religious; tolerance; personality; human rights; university; liberation theology 


\section{Introducción}

A fines del siglo XX y comienzos del XXI transformaciones importantes ocurrieron en América Latina y el Ecuador en el campo de su vida religiosa y espiritual. El peso gravitacional de la Iglesia Católica giró alrededor a determinados líderes religiosos entre los cuales consta el arzobispo Luis Alberto Luna Tobar. Innovaciones distintas en las comunidades eclesiales de base abrigaron escenarios frente a la influencia de la teología de la liberación. Se interesa recoger los aportes, las consonancias y disonancias entre el mundo religioso y secular ocurridas en torno a la época en donde le toco ejercer de pastor Luna.

\section{Metodología}

El presente escrito, recrea las ejecutorias de un obispo católico en una ciudad Andina de fuertes tradiciones. Se recurre a un enfoque inductivo de sus actividades tanto religiosas como laicas, tomando herramientas de la memoria y de su paso histórico, y a la vez mediante entrevistas seleccionadas consultar sobre el entorno eclesiástico, doctrinal y social durante las épocas previas en donde diferentes escuelas teológicas entre progresistas y tradicionales impregnaron el mapa de América Latina.

Por razones éticas ligadas a la investigación y por transparencia, se decidió barrer el documento por el sistema anti plagio Urkund cuyo resultado demostrando la idoneidad del trabajo consta en el Anexo 2.

\section{Monse Luna, maestro de maestros.}

Con ese pergamino escrito con letras transparentes -como la juventud universal lo ha sido siempre- Monse Luna, -como le llamaba Cuenca al arzobispo Luis Alberto Luna Tobar- fue condecorado por la Asociación Escuela de Jurisprudencia, Ciencias Sociales y Políticas de la Universidad de Cuenca. El rector de ese entonces (coautor del presente trabajo) del alma mater morlaca acompañó aquel día la ceremonia en el Aula Magna 'Hugo Ordoñez Espinosa', cuando los alumnos presididos por su presidente, Darío Ordoñez Aray, le ofrecieran así su corazón y firma. Extraña acción en el espacio celoso de una universidad pública y laica.

Cabe aclarar el término "laico"; la Real Academia de la Lengua Española lo define como "Independiente de cualquier organización o confesión religiosa." Por su parte el "laicismo" es definido por el mismo diccionario como "Independencia del individuo o de la sociedad, y más particularmente del Estado, respecto de cualquier organización o confesión religiosa." (Real Academia Española, 2017) 
Es que Hidalgo ${ }^{1}$ (Instituto Nacional de Solidaridad, 1993) y Morelos ${ }^{2}$ (Gutiérrez Escudero, 2008) fueron sacerdotes, pero fundaron el México postcolonial. Es que Fray Jodoco Rique $^{3}$ (Navarro, 2007) el franciscano belga flamenco fue quien según se atribuye, sembró el primer grano de trigo en Sudamérica, inició la construcción del templo de San Francisco en Quito y continuó el de Popayán, además de haber sido defensor de los indios y creado la escuela de artes y oficios San Andrés de la escuela quiteña ${ }^{4}$. Es que Fray Bartolomé de las Casas 5 (Martínez Torrejón, s.f.) fue defensor de los indios -aunque su argumento de conceder razón para ello a partir de estimular el esclavismo negro continúa en el debate. Es que Juan de Palafox ${ }^{6}$ (Fernández de Zamora, 2011), obispo y virrey fundó la más impresionante biblioteca del nuevo Continente en Puebla. Y es que sor Juana Inés de la Cruz (Aguilar Salas, 20157) , a pesar de ser monja, fue el mexicano (no solo la mexicana) más importante de la historia según el premio Nobel Octavio Paz. Por cierto, que los excesos de todas las religiones son abundantes. Baste citar las cruzadas y la inquisición en el caso del cristianismo. José Peralta ${ }^{8}$ (Avilés Pino, s.f.) fue de los mayores críticos del monaquismo y sus trastiendas en el país. El propio García Moreno ${ }^{9}$, (Ayala Mora, 2015) contradictoriamente y a pesar de su gobierno teocrático, se embarcó en la tarea cuesta arriba de moralizar al clero relajado.

Respecto del clero, "Ha habido etapas positivas y negativas; las negativas son aquellas en donde se imponían las ideas sin restricción alguna a los demás, y penosamente con mayor intensidad a los más pobres de nuestros países y de otros países más civilizados. En la etapa actual su papel es ponderado y adecuado sin dejar de mencionar abusos específicos de ciertos

\footnotetext{
${ }^{1}$ Miguel Hidalgo y Costilla nació en Guanajuato, México en 1753. Fue catedrático de teología, filosofía y moral. Adicionalmente, se ordenó como sacerdote y fue uno de los personajes importantes que lucharon por la independencia de México.

2 José María Morelos nació en Valladolid, México en 1765. Jefe del ejército insurgente, sacerdote que participó en el proceso independentista de México.

${ }^{3}$ Introdujo en Quito el arte del renacimiento. Edificó la iglesia y el convento de San Francisco.

${ }^{4}$ Lo bueno va de la mano con lo malo: este gigante flamenco universal vino a las Américas en la expedición que comandara Pedro de Alvarado al Perú. Pedro de Alvarado posiblemente el conquistador más perverso de todos, genocida de los indios americanos.

5 Ícono político y social nacido en Sevilla. Fue catequista, soldado y se ordenó como sacerdote. Personaje importante en la lucha en defensa de los indios en Cuba, capellán de la compañía de Pánfilo de Narváez entre 1512 y 1514.

${ }^{6}$ Nació en Fitero-Navarra en 1600. Fue arzobispo y virrey de la Nueva España y obispo de Puebla en el siglo XVII. Estudió derecho y estuvo al tanto del desarrollo de las bibliotecas ya que estuvo relacionado con la corte, espacio donde las bibliotecas eran muy importantes.

${ }^{7}$ Nació en 1651. Novicia que sobresalió en la escritura y administración del convento donde fue contadora 9 años. Escribió villancicos, poemas que la consagraron como poeta. Famosa por sus sonetos, romances, redondillas, endechas, liras y otros géneros líricos. Además, escribió dos comedias de teatro conocidas como comedias de enredo.

${ }^{8}$ Nació en 1855 en Chaupi-Yunga, Azuay, actual provincia del Cañar. Fue un filósofo, escritor liberal y doctor en Jurisprudencia. Fue co creador del Partido Liberal y pese a estar expuesto a todo tipo de ataques, publicó una serie de escritos y artículos a través de los cuales defendió su postura política. Preparó las bases ideológicas que culminaron con el triunfo de la Revolución Liberal en 1895. Fue Rector de la Universidad de Cuenca y Canciller de la República. Uno de sus libros se llamó precisamente El Monaquismo.

${ }^{9}$ Expresidente del Ecuador. Figura que ha causado debate sobre su personalidad entre las posturas de los conservadores católicos que lo califican como ejemplar y mártir de la fe; y los liberales militantes laicos que lo denuncian como tirano y represor.
} 
sacerdotes y frailes, pero ya no de una iglesia como todo sino de ciertos miembros negativos de esa iglesia." ${ }^{10}$ (Chiriboga, 2017)

\section{'Si luego de morir no le encuentro a Dios, le seguiré buscando'}

Así, arrobado de lucidez, lo decía Monse, nos recuerda Luciano Bellini, ex rector de la Universidad Politécnica Salesiana. Fue siempre un buscador inconforme. No hubo para él verdades cerradas, jamás el fanatismo circuló por sus arterias, la ortodoxia no se registraba en su diccionario -sin abdicar, sin embargo, de esas vehemencias y sobresaltos guturales que la vida sin hipocresías le enseñó a exaltarse con pasión y verbo-.

\section{La blasfemia, esa oración con rabia}

Abierto a las corrientes del mundo, estudioso humilde de los sentires hondos del pueblo llano, discreto siempre con los escondrijos que las ciencias encierran, más herméticas que visibles, Monse edulcoraba el agnosticismo que la vida tantas veces nos precipita ante un mundo injusto, con un pensamiento trascendente: "La blasfemia -recitaba- es una oración con rabia". Justificaba la rebelión contra Dios, quizá la búsqueda de otra forma de Dios, a partir de la evidencia y constatación de un mundo incompleto. "Después de la vida, la libertad es el mayor de los dones y valores de una persona y una sociedad. Como consecuencia de esto, la libertad sea política o religiosa es muy importante, cada persona tiene derecho a escoger su camino. La vida por sí sola no tiene sentido si no eres libre; sin embargo, la libertad de un persona termina cuando empieza la libertad de otra persona" 11 (Chiriboga, 2017)

\section{'El pueblo me evangelizó'}

Le conocimos en Pillachiquir y sus flores color azafrán por doquier en la montaña, loma arriba de Quingeo y Cumbe, cuando junto con Monseñor Leonidas Proaño ${ }^{12}$ (Agencia pública de noticias del Ecuador y Suramérica, 2016) visitaran hace tanto, la comunidad campesina indígena. Chofer de su propio jeep, sin "guaruras" a protegerle, como el poder acostumbra acolitar el narcisismo de la autoridad, sin poses ni parafernalias, como aquellas que el poder no sabe de vacunarse, sin atuendos purpurados, colores del boato de la jerarquía; su activo fijo fue su sonrisa diáfana, sin esas ficticias muecas y pliegues de la piel que la vanidad dibuja en artificio.

Departimos el diálogo, las propuestas, las quejas, la generosidad a quemarropa que solo las manos rurales saben de regalar, la pampamesa final junto al fogón de leña como epílogo de la faena.

"El pueblo me evangelizó", fue su constante. Lo decía y sobre todo lo sentía. Cuan distintas eran las breñas andinas, el andar en cadencia a lomo de mula, caballo o asno - réplica

\footnotetext{
${ }^{10}$ Entrevista a Bolívar Chiriboga en octubre de 2017.

${ }^{11}$ Entrevista a Bolívar Chiriboga en octubre de 2017.

${ }^{12}$ Nació en San Antonio de Ibarra en 1910. Referente del mensaje de liberación y del trabajo desinteresado hacia los más pobres. Fue sacerdote y trabajó con campesinos y obreros católicos. Luchó contra la explotación de terratenientes, comenzó a alfabetizar a indígenas en su lengua materna y enseñó aritmética. Fue el primer ecuatoriano candidatizado en 1986 al Premio Nobel de la Paz.
} 
del Domingo de Ramos bíblico- respecto de los oropeles atrás del altar mayor de la iglesia de Santa Teresita en el norte aburguesado de Quito, la magnífica, la capital, la matriz de la escuela de artes y oficios, pero a la vez, la Quito de racimos aristocráticos inventados, que le habían confundido en su primer ejercicio profesional de sacerdote.

\section{La blasfemia de la teología de la liberación}

\section{Mutación y transustanciación}

Contribuyeron para su "radical" posición, su amistad con Leonidas Proaño, candidato siempre perdedor a premio Nobel de la Paz, distante de los terciopelos de la impalpable Oslo de Noruega. Proaño, nacido en la cuna llana de San Antonio de Ibarra -Belén ecuatoriana para él- le enseñó de la magia de la gubia y el cincel, que los mejores artesanos en labrar la madera del país, profesan día a día. Ya de obispo en Riobamba, sus escuelas radiofónicas populares, el sentir hondo y sin poses frente al "Hombre del Chimborazo", con Federico Aguiló ${ }^{13}$ (Aguiló, 1992) y su estremecedor libro, sus coqueteos primero y su adopción plena luego con la iglesia de los indígenas, habían dado forma y fondo a su ejercicio pastoral en la provincia más inequitativa, más racista, más feudal-esclavista de la sierra ecuatoriana. "Antes la iglesia encerrada en sus colegios o universidades no trascendía, su trabajo no llegaba hacia los más necesitados tal como habla el evangelio. Esta nueva visión teológica, planteaba un cambio profundo para que la gente no vaya a la iglesia sino la iglesia vaya a la gente." ${ }^{14}$ (Velasco, 2017)

Un báculo en Monse Luis Alberto Luna Tobar, durante su proceso de toma de conciencia popular, fue su amistad con Leonardo Boff ${ }^{15}$ (Vázquez Carballo, 2008). Se participó en una reunión abarrotada de campesinos en el local ciudadano que, para sus reuniones y luchas, tenía la UNASAY, cercana a la ECUARUNARI actual, en la calle Larga de Cuenca, cuando Monse Luis Alberto, le acompañó a Boff para que conversara con los campesinos del Azuay, aquellos que habían perdido su lengua madre, debido a la alienación histórica del enhacendado, heredero del encomendero colonial.

Monse Luna siguió sus lecturas, pero se mantuvo en la orden religiosa y en el rol de pastor del arquidiócesis de Cuenca. Apreció y cosechó Monse, la experiencia de vida y las convicciones de Boff, pero desechó como tentación para sí, la decisión del brasileño de "cambiar de camino, pero no de dirección", cuando abandonara la orden, el sayal y el cordón de San Francisco, ante el anatema que el papa polaco Juan Pablo II había tatuado sobre la Teología de la Liberación Latinoamericana, tal como lo hizo con su dedo admonitivo sobre una cabeza reverente y sin su boina negra habitual del poeta y ministro de cultura del sandinismo nicaragüense de Ernesto Cardenal, censurando su opción política en su condición simultánea de sacerdote.

\footnotetext{
${ }^{13}$ Sacerdote con un profundo deseo de encarnarse en la vida del indígena andino. En varias ocasiones ha afrontado diversos problemas, destierros, calumnias y malentendidos. Ha sido profesor en universidades de Bolivia y Argentina; ha trabajado también en varias parroquias del Chimborazo en Ecuador.

${ }^{14}$ Entrevista al Dr. Edgar Velasco en junio de 2017.

15 Brasileño, teólogo de la liberación que entre otras obras escribió: "Los sacramentos de la vida", "Jesus Christ libertador" y "Cry of the earth, cry of the poor".
} 
Se visitó, aprovechando encuentros universitarios, la parroquia distante de la Lima virreinal, más próxima al Callao, en donde Gustavo Gutiérrez ${ }^{16}$ (Pontificia Universidad Católica del Perú, 2004), otro sacerdote emblemático, cofundador de la tendencia de la Teología de la Liberación, ejercía su rol de párroco y acompañante de las vicisitudes diarias de la pobreza suburbana. En la vida estudiantil era usual alimentarse de los legados de Helder Cámara ${ }^{17}$ (Encyclopaedia Britannica, s.f.), y su obispado a contrapelo del poder eclesiástico en la Recife tercermundista de un Brasil vulnerable.

Se bebió de los excesos de Méndez Arceo ${ }^{18}$ (Hernández Vicencio, 2012), el obispo rojo de Cuernavaca, allí en Morelos en donde Emiliano Zapata ${ }^{19}$ (Encyclopaedya Britannica) había nacido, "ejercido" la revolución mexicana desde el sur y, en donde también fuera inmolado. Crecimos con las lecturas modernizantes del Concilio Vaticano II ${ }^{20}$ (Morales, 2012) convocado por Juan XXIII, el papa rechoncho, diáfano y visionario. Crecimos con los aportes "distintos" de los encuentros de Puebla y Medellín, que habían dimensionado otra forma de sobrepasar la molicie de una Iglesia trasnochada.

Y para volver nuevamente a México, tiempo después se visitó y dialogó con los campesinos indígenas de la exultante y verde Chiapas, en San Bartolomé de la Casas ${ }^{21}$, en donde el obispo Samuel Ruiz ${ }^{22}$ (Bonner, 1999) había fundado su templo-trinchera y sus seguidores vivían aún su pedagogía del oprimido, como gustaba decir desde el otro extremo del Cono de las Américas, Paulo Freire. Chiapas, en donde nació el Ejército Zapatista de Liberación NacionalEZLN- y su guerrilla romántica y desarmada, cuando en fecha coincidente, el 17 de diciembre de 1992, en el que México de Salinas de Gortari, alucinado de alienación norteamericana, firmara el Tratado de Libre Comercio con Estados Unidos y Canadá -NAFTA extraviando su origen y destino al sur del río Grande.

Tanto castiga la historia que hoy, 2017, el presidente de Estados Unidos Donald Trump trabaja para darle de baja a dicho Tratado. Salinas discurseaba a la fecha, que México había salido del subdesarrollo y había iniciado su apuesta por insertarse en el mundo del éxito del

\footnotetext{
${ }^{16}$ Peruano, teólogo de liberación que entre otras obras publicó: "La espiritualidad de la liberación”, y "Del lado de los pobres, teología de la liberación."

${ }^{17}$ Arzobispo católico de raíces afro brasileñas, puso una impronta fundamental en torno a las barriadas pobres de la ciudad de Recife, una de las más necesitadas de Brasil. Su colección de discursos y sermones en campos sociales fueron publicados bajo el título original de: "Revolução dentro da paz."

${ }^{18}$ Fue uno de los teólogos más radicales de la iglesia latinoamericana, radicado en la ciudad de Cuernavaca en el Estado de Morelos, México. Denominado el obispo rojo de Cuernavaca. Precursor de estrategias diferentes de organización en el campo de movimientos sociales.

${ }^{19}$ Revolucionario mexicano, campesino de la provincia de Morelos que comandó el ejército revolucionario del sur contra la dictadura de Porfilio Díaz, junto a Pancho Villa que comandó el ejército revolucionario del norte; se tomaron la ciudad deMéxico. Diezaños que duró la Revolución Mexicana que dejó más de un millón de muertos.

${ }^{20}$ Lo inició el papa Juan XXIII en 1959 y finalizado por el Papa Pablo VI. Su objetivo fue desarrollar la fe católica, renovar la moral de los fieles, promover la disciplina eclesiástica en nuestros tiempos. Este concilio ha dejado una huella en la historia de la iglesia.

${ }^{21}$ Cuando Gustavo Vega sirvió al país en calidad de Embajador plenipotenciario en México entre el 2000 y 2003

${ }^{22}$ Ruiz de Chiapas; En parte por la pedagogía y la práctica pastoral de Ruiz, los campesinos e indígenas del sureño estado mexicano de Chiapas, se convirtieron con el tiempo en insurgentes. Cristalizó su posición finalmente en la creación del ejército zapatista de liberación nacional, comandada por el subcomandante Marcos. Se trató sin embargo de una guerrilla no armada, apoyada fuertemente por grupos radicales de Italia y España a los que se les denominó los "monos blancos".
} 
hemisferio Norte. Hasta el poeta revolucionario centroamericano Tomás Borge ${ }^{23}$, en tiempos de expropiaciones mentales, se confundió tanto, que escribió un libro panegírico en favor del descastado Salinas! ¡Mal paga el diablo a sus devotos!

Con el andar del tiempo se visitó con angustia y estupor la capilla breve del hospital en donde el obispo Romero ${ }^{24}$ (Mata, 2015) de San Salvador fuera acribillado mientras daba misa. Y el museo de la memoria en donde jesuitas comprometidos con el pueblo enseñando en la Universidad amparada por la orden de san Ignacio de Loyola ${ }^{25}$, José Simeón Cañas, fueron ejecutados a mansalva en el país pulgarcito de América, cuando vivió extremismos increíbles.

Es justificable a plenitud que el papa argentino Francisco haya decidido recientemente la canonización del obispo mártir salvadoreño. "Fue un grupo de 6 jesuitas, 4 de ellos fueron mis compañeros. Vinieron a estudiar en Ecuador filosofía y a hacer su Juniorado, se empaparon de toda la problemática latinoamericana, hicieron trabajo social en la universidad, entre muchas actividades importantes en beneficio de la comunidad. Lamentablemente el ejército y el Estado no vieron sus acciones positivas y les pusieron muchos límites; de manera atroz una noche llegaron tres pelotones de militares armados, mis compañeros llegaron de trabajar y en su casa descansando les sorprendieron, les sacaron y les dispararon.” ${ }^{26}$ (Velasco, 2017).

Un conjunto de insumos, de influencias y brújulas sobre Luis Alberto Luna Tobar, finalmente se condensaron en el proceso de su "transustanciación" -para tomar una metáfora cristiana-, de su "mutación" -para echar mano de una metáfora de la biología- en la vida y obra de nuestro Maestro de Maestros.

\section{La ambivalencia del origen}

Nacido en cuna aristocratizante ibarreña-quiteña, mutó su "origen" de clase, asumiendo una "conciencia" y una "posición" de clase en favor de la orilla del pueblo, para seguir las añejas categorías de Marx. Su inscripción en la orden religiosa O.C.D. del Monte Carmelo, de los carmelitas descalzos en la línea de San Juan de la Cruz y Santa Teresa de Ávila, doctores de la Iglesia, le ayudó a Monse, nuestro Monse Luna Tobar, atrás del telón de su rol de pastor, en su búsqueda y re encuentro que sin embargo sólo le entregó después y del todo la vida, a través de su verdadera identidad lograda en plenitud de madurez en Cuenca, su provincia y sus secretos.

Su formación de novicio en Burgos, la de la Catedral magnífica y su acendrada vocación religiosa, jugó una impronta indeleble, conforme en tertulias itinerantes de amigos, lo confesaba con transparencia.

\footnotetext{
${ }^{23}$ Poeta nicaragüense, escritor de: "El arte como herejía: la cultura en la memoria y la vida de T. Borge", "Woman and the Nicaraguan revolution". Encarcelado por el régimen de Somoza. Cometió la ingenuidad de escribir una biografía sobre el presidente mexicano Salinas de Gortaire.

${ }^{24}$ Arzobispo salvadoreño que nació en 1917 y fue asesinado en 1980. Declarado mártir en febrero de 2015 por el Papa Francisco, estuvo asociado a movimientos sociopolíticos de corte izquierdista.

${ }^{25}$ Nació en 1491 en el castillo de Loyola, país vasco, junto a Azpeitia, caballero al servicio de Carlos I de España y V de Alemania. Fundador de la Compañía de Jesús, la orden religiosa de mayor y profunda influencia en el pensamiento y la sociedad universal, en especial occidental.

${ }^{26}$ Entrevista a Edgar Velasco en junio 2017.
} 


\section{Estrategias taurinas}

Una rara habilidad de Monse fue la de sortear con estrategias taurinas -que en su juventud ruedo, arrojo, capa y arena le enseñaron- las antinomias que la vida cotidiana exige: se codeaba sin contaminarse- con el poder local y nacional, ejercía su rol de periodista de opinión escribiendo en rotativos nacionales y locales, en la prensa siempre concentradora de poder. Asistía y dialogaba con universitarios, estudiantes y maestros en sus tertulias más que de café, conferenciaba en la universidad laica, la que le sentía más suya que los curuchupas citadinos le sentían a él, que merodeaban para influir sobre él o cosechar canonjías. Se llevaba sin discriminar con burgueses, intelectuales, obreros, sindicatos, campesinos e indígenas, sin claudicar y siempre pensando que la lucha de clases marxista, quizá ya no reinaba del todo como Marx dictaminara illo tempore y que a la luz de raíces distintas y de un nuevo orden de cosas, Latinoamérica no copiaría a raja tabla. Así lo entendió Carlos Mariátegui ${ }^{27}$ (Biografías y Vidas, s.f.) desde el Perú, cuando exponenció el materialismo dialéctico e histórico con los aportes propios de una América Latina no europea, pero siempre irredenta.

\section{La homilía como ráfaga}

Sus homilías en la Catedral Nueva convertían su voz estridente de pasión, en ráfaga, brisa y frescor. Sus homilías súbitas como el relámpago, tronaban en el baldaquino y las columnas tejidas en oro ensoguillado -a imagen de la Basílica de San Pedro en Roma- de esa iglesia enorme que había diseñado en planos el redentorista Stielhe y que tomó 90 años construirla, iniciada por el obispo León Garrido y aún hoy se expresa todavía inconclusa. Como tampoco la iglesia de la Sagrada Familia en Barcelona, diseño y obra de Antonio Gaudí ${ }^{28}$ (Van Hensbergen, 2003) se termina aún. Como Schubert ${ }^{29}$ (La Estrella de Panamá, 2015) tampoco terminó su gloriosa Sinfonía Inconclusa.

Semejante a Oswaldo Guayasamín ${ }^{30}$ (Fundación Guayasamín , s.f.) que acuarelaba sus retratos en cuestión de minutos, así el maestro de la palabra alada, Luis Alberto Luna, acuarelaba su mímica, dicción, semiótica y semántica en cuestión de minutos. Difícilmente sus homilías pasaban de cinco minutos. Su cabeza nevada por el tiempo y la genética, no era ajena a los berrinches de los niños en la misa, los aceptaba con honda resignación y realismo, pero tampoco su velocidad dejaba lugar para un bostezo de aburrimiento. "Si lo bueno breve, dos veces bueno", al decir de Honoré de Balzac.

\footnotetext{
${ }^{27}$ Pensador peruano reconocido como los más influyentes de América Latina, declarado "marxista convicto y confeso" que fundó el Partido Socialista además de la Confederación General de Trabajadores. Entre sus obras más importantes se destaca "Siete ensayos de interpretación de la realidad peruana" (1928), mismo que constituye un paradigma de análisis en ámbitos políticos, sociales y culturales

${ }^{28}$ Arquitecto catalán, genio modelo del diseño cuya escuela ha sido bautizada con una arquitectura escultórica. Obras de él son: "La Iglesia de la Sagrada Familia", "La casa pedreras", "Parque Güell”, entre otras hermosas e impresionantes.

${ }^{29}$ Franz Schubert, músico que, al fallecer con apenas 31 años de edad, entregó más de 900 obras musicales en casi todos los géneros. Una de sus más famosas es la "Sinfonía inconclusa", llamada así ya que compuso los dos primeros movimientos, pero no los cuatro que caracteriza dicho género.

${ }^{30}$ Nacido en Quito en 1919 de ascendencia indígena. Con tan sólo 7 años de edad, Oswaldo Guayasamín empieza a pintar sus primeras obras
} 
Esa Catedral, es la que hoy hace guardia celosa de su legado y restos mortales en sus criptas subterráneas. Catacumbas que como las de los primeros cristianos perseguidos por el Imperio Romano, habían obligado a credo, fe y liturgia primitivos a asumir una práctica rebelde, secreta, hermética, subterránea, clandestina, tupamara- perdón por el anacronismo-. No en vano la palabra "cripta" viene de "críptico", escondido, encerrado, secreto.

\section{La bisectriz del ángulo entre tradición e innovación.}

Fiscal de la oligarquía, defensor del pueblo pedestre, activista de los derechos humanos, crítico del fetichismo religioso, sin denostarlo, no se dejó adular Luis Alberto Luna del clero trasnochado, hizo equipo con sacerdotes jóvenes y respetó a los viejos, pero entendió y aplicó aquello que la Iglesia no es su jerarquía -equívoco perverso- sino la comunidad espiritual toda.

Cuenca venía de ser tradicionalmente la Meca del conservadurismo nacional, en donde la Iglesia era particularmente fuerte. Sacerdotes influyentes entre tantos fueron el obispo Victor J.

Cuesta que a la vez fuera nombrado en su tiempo rector de la Universidad. Nicanor Aguilar que tuvo por su parte impacto reverberante. El mercedario Julio María Matovelle, orador sagrado único y diputado y, en tiempos de apasionado velasquismo, el cura Terán Zenteno que ejercía un poder inusitado sobre la ciudad a partir de su periódico "Diario del Sur” y sus polémicas entregas. Abrirse espacio diferenciado y progresista en una ciudad de tradiciones venía a constituirse en un desafío complejo para Monse Luna Tobar.

Si por algo no aupaba la fiesta cultural del Pase del Niño en la Cuenca de los 24 de diciembres, lenguaje de una sentida y colorida identidad mixtificante, multitudinaria cada vez más, es precisamente por su convicción que no debía confundirse fetichismo con religión; expresiones y lenguajes que no podían ser comparados con el hondo y a veces inefable sentimiento de la mística profunda. Se ha discrepado con Luis Alberto respecto de esta convicción y práctica, quizá por algún desvío profesional en el campo de la psiquiatría y de la antropología, al pensar que religión y cultura son un todo envolvente sin fronteras.

Aceptó con madurez y tolerancia la condición confesa de panteísta de alguno de los contertulios. Tantas veces se compartió en su despacho de la Curia, en su casita atrás las aguas del Tomebamba o en los cenáculos cívicos o universitarios, que las religiones amerindias, antes de ser cristianizadas, fueron un panteísmo puro, mucho antes que haya nacido Barugh de Spinoza. Pachamama, las variantes de ucu pacha, pai pacha, chaupi pacha y tantos rostros telúricos de la multi dimensión conceptual de la tierra, que ninguna lengua occidental acumula tanto en su pensamiento, son parte de un panteísmo andino y americano que no soñara la cristiandad. El mundo de los Apus andinos, Viracocha, las leoquinas cañaris, la Guacamaya y la Serpiente, más que animismos y animatismos, a la lógica de la cultura occidental, encerraban la sede y el templo de una espiritualidad superior, en donde el Universo todo asumía el símbolo y la identidad de la sacralidad. 


\section{Los derechos humanos, pensamiento y activismo}

La faceta de Monse en el campo de los derechos humanos unió -con suelda autógena- el espíritu y vocación de algunos activistas. Se aprendió de él a ser directo y mordaz con la injusticia. Durante muchos años cuando Monse presidiera la Comisión Ecuménica de los Derechos Humanos y, en el cese de uno de los coautores de este trabajo, presidiera en el capítulo nacional, Amnistía Internacional, se publicó, se escribió, pero, sobre todo, se vivió y compartió la sabiduría y emblemas de la defensa enconada, si es preciso, de los derechos humanos. Monse vivió los derechos humanos no como una herramienta academicista y de oropel intelectual, lo hizo con el látigo de Jesús, sacando a los mercaderes del templo, pero sin perder jamás el poder de convencimiento de la pluma al momento de prevenir, proteger, promocionar los valores de la vida, la seguridad, la justicia cotidiana, la ética, la estética.

Presidió Monse la Comisión de la Verdad para esclarecer los crímenes contra los derechos en un régimen de oprobio que vivió otrora el Ecuador. De la misma manera como Salomón Lerner Febres, ex rector de la Pontificia Universidad Católica del Perú lo hiciera con relación a los excesos en tiempos de Fugimori; como presidiera comparativamente el escritor Ernesto Sábato $^{31}$, la comisión respectiva en Argentina para esclarecer los crímenes horrendos durante la feroz dictadura entre 1978 y el 83. Pero a la vez, Monse Luna exorcizó como Cristo las tentaciones del demonio, las itinerantes propuestas para que acepte las primeras magistraturas políticas del país, especialmente luego de intensas crisis y graves convulsiones nacionales.

Su amistad no extraviaba su ideología. Alguna vez, hubo un exabrupto que precipitó un escabroso momento de afectación a los derechos humanos en la Universidad. No vaciló en criticarlo. No dudó un segundo, no cabía asumir un espíritu de cuerpo. Aquello podía ser válido en lógicas castrenses o policiacas, al amparo equivocado de una mal habida protección de la institucionalidad. El rector de ese entonces ${ }^{32}$ (1998) convenció con creces al Consejo Universitario, para ventilar el hecho con una sentencia directa y sin mimetismos, convencido a su vez de que la impunidad recrea el error.

\section{Reír es tomar las cosas en serio}

Un campo magnífico de la personalidad de Luis Alberto Luna, fue su exquisito sentido del humor. Su sonrisa transparente se convertía con frecuencia en risa diáfana para festejar el chiste ajeno o la ironía propia. Recitaba con fino humor respecto de vulnerabilidades personales de sus contertulios que "los pecados capitales no necesitan confesarse. Que sólo los veniales."

\section{Demasiado viejo para jubilarse}

Así decía de sí mismo el filósofo oriental Confucio, cuando le recordaban su edad y su incansable trabajo. Monse Luna decidió jubilarse y seguir laborando. El pecado de "cometer" trabajo. No podía concederse pausas. Las universidades recibieron su itinerante cátedra abierta.

\footnotetext{
${ }^{31}$ Autor de "El túnel", "La resistencia" y "Hombres y engranajes

32 Gustavo Vega Delgado
} 
La fundación Donum bajo su presidencia siguió activa. En lo familiar, sus cruzadas fueron cotidianas. No hay familia en Cuenca y el Azuay, que algo o mucho haya recibido de la generosidad espiritualidad a raudales que los casi 19 años de ejercicio religioso arzobispal pusieron las manos de Monse Luna Tobar. Y un adicional de yapa y paltana, pues después de terminar su misión oficial, decidió continuar viviendo y produciendo en Cuenca durante largos y renovados años, ya como ciudadano normal y corriente, antes de su retiro a su Quito natal por motivos de salud.

\section{El polvo del todo y de la nada}

Su epitafio escogido por él mismo dice mejor, al tenor de la sencillez de los carmelitas descalzos: "Aquí está el que fue". Me recuerda la sencillez franciscana y la convicción plena de la limitación humana de Fray Junípero Serra ${ }^{33}$ (Palou, 2002), caminante desde la Sierra Gorda de Querétaro rumbo a California, fundando misiones a su paso hasta tocar San Francisco, quien asumió el sustantivo propio Junípero, precisamente para compararse con lo insignificante que representa la levedad sencilla del término lingüístico, el sustantivo común, junípero.

Por otro lado, recuerda el epitafio de Monse, a la leyenda colocada sobre un cráneo nacarado que sirviera en aprendizajes de anatomía humana cuando estudiantes de medicina. "Soy el que serás.

Fui lo que eres", rezaban lapidarias esas letras que traducían toda una filosofía de la transitoriedad parva, banal y nada venal de la condición humana, frase tremenda al momento de reconocer la incurable contingencia y futilidad frente a la insondable muerte. Somos polvo de estrellas y a ellas regresamos, diría Ernesto Cardenal ${ }^{34} \mathrm{en}$ su 'Cántico cósmico'.

\section{La Universidad, su templo universal}

Cuando una candidatura para presidente del Consejo Nacional de Educación Superior CONESUP ${ }^{35}$ - en el 2006 se difundía entre las universidades, las escuelas politécnicas, los institutos superiores técnicos, tecnológicos, entre los otros componentes de profesionales de los electores y, se requería también el apoyo del vicepresidente y del ministro de educación y cultura desde el gobierno nacional, su recomendación a favor le espetó a boca de jarro al presidente de la República Alfredo Palacio, un 12 de abril, fiestas fundacionales de Cuenca. Su argumento paralizó al presidente del Ejecutivo de entonces. Su sentencia sonó imperativa: "Se trata de que apoyes a un hermano, hermano en las luchas de la universidad y de la vida". Sus palabras quedaron indelebles en la insolvente gratitud del recipiendario. Pues en efecto el complejo y múltiple colegio electoral provocó una elección por unanimidad en el entonces Tribunal Supremo Electoral en julio de 2006.

\footnotetext{
${ }^{33}$ Junípero Sierra: Sacerdote franciscano que tuvo una actividad intensa entre México y Estados Unidos recorriendo a pie y fundando misiones desde la Sierra Gorda de Querétaro hasta San Francisco de California. Las misiones de Querétaro fueron luego declaradas patrimonio de la Humanidad.

${ }^{34}$ Poeta, autor de "Hacia el hombre nuevo", "El exteriorismo poesía del nuevo mundo", entre otros.

${ }^{35}$ Gustavo Vega Delgado
} 
Las festividades de los sábados de mayo, que inauguró el rector Honorato Vásquez ${ }^{36} \mathrm{se}$ mantiene vinculando literatura mariana con vida universitaria aún hoy. Luis Alberto Luna fue en su tiempo arzobispal el mayor de los mantenedores de la tradición junto al académico y escritor Juan Cordero Iñiguez, en cuyos espacios se aprovechó para siempre publicar bibliografía cultural, en favor del arte y de los símbolos. Un ensayo espiritual interesante al interior de una universidad pública.

Quizá, en el único espacio real en donde se sentía Luna con entera libertad para decir lo que pensaba fue en la Universidad. Percibía que solo allí no había censuras ni grilletes mentales. Que, siguiendo a Ortega, la 'universitas' era la conciencia crítica de la sociedad. Que no pocas veces fue 'institución ultrajada', como Pérez Guerrero ${ }^{37}$ (Historia de la procuraduría general del Estado, s.f.) enseñara. Que siguiendo a Jaques Derridá ${ }^{38}$ (Krieger, 2004), la universidad era la única institución 'sin condiciones', sin hipotecas ideológicas que arriesguen su pensamiento libre.

Que, como Hernán Malo ${ }^{39}$ (Ayala Mora, y otros, s.f.) filosofaba, era 'sede de la razón e institución perversa' para el poder. Lamentablemente con otras disonancias y consonancias repetidas en tiempos del gobierno Correísta por su afectación sistemática de la autonomía universitaria. Entraba Monse Luna en la Universidad, como Pedro en su casa.

"Creo que Luna Tobar es un ejemplo de la manera más inteligente de no solo decir, sino de hacer, más allá de que nunca calló ante la injusticia ni ante lo incorrecto en el seno de su trabajo, ni en la política nacional." ${ }^{40}$ (Salazar, 2017)

¡Tanto le admiramos, tanto le respetamos, sobre todo, tanto le amamos! Para jugar con los retruécanos: ¡Le respetamos y admiramos sí, pero por haberle amado! Jamás al revés. Su inmortalidad está en la memoria inagotable que guardamos de él.

\section{Bibliografía}

Agencia pública de noticias del Ecuador y Suramérica. (2016). ANDES. Agencia Pública de Noticias del Ecuador y Suramérica. Obtenido de http://www.andes.info.ec/es/noticias/monsenor-leonidas-proano-taita-guia-indigenas.html

\footnotetext{
${ }^{36}$ Abogado, poeta, diplomático, educador y escritor cuencano, a la edad de 20 años publica su primer libro de versos, luego obtiene el título de abogado, diputado de la Asamblea Nacional Constituyente, secretario delegado para arreglo de límites con Colombia, Diplomático e Internacionalista, murió en Cuenca en 1933. Rector de la Universidad de Cuenca, diplomático. La escuela de Relaciones internacionales de la Universidad Central del Ecuador lleva su nombre, quichuista, pintor. Fue declarado por las instituciones de Cuenca como el cuencano más importante del siglo XX.

${ }^{37}$ Alfredo Pérez Guerrero nació en Ibarra en 1901.Abogado, periodista, escritor y académico que ocupó varios cargos públicos, entre los más importantes como procurador. Rector de la Universidad Central del Ecuador.

${ }^{38}$ Filósofo francés, académico y creador de corrientes sobre pensamiento universitario. Comprometido con los derechos humanos que apoyó a Nelson Mandela en Sudáfrica.

${ }^{39}$ Personaje importante para la construcción de una praxis de filosofía considerada como un recomienzo filosófico en el Ecuador. Rector de la Pontificia Universidad Católica del Ecuador, creador de distintas corrientes del pensamiento universitario, filósofo formado en Alemania.

${ }^{40}$ Entrevista a Richard Salazar en junio de 2017.
} 
Aguilar Salas, L. (2015). Biografía de Sor Juana Inés de la Cruz. Universidad del Claustro de Sor Juana.

Aguiló, F. (1992). El hombre del Chimborazo. En F. Aguiló, El hombre del Chimborazo. Cayambe: Abya- Yala.

Avilés Pino, E. (s.f.). Enciclopedia del Ecuador. Obtenido de http://www.enciclopediadelecuador.com/personajes-historicos/dr-jose-peralta/

Ayala Mora, E. (2015). García Moreno y su régimen entre la vieja y la nueva historia. Una polémica anacrónica. Revista procesos, 203- 226.

Ayala Mora, E., Hernández Alvarado, J., Aguilar Cuenca, J., Paladines, C., Panchi, L., Roig, A., (s.f.).

Biografías y Vidas. (s.f.). Biografías y Vidas. La Enciclopedia Biográfica en línea. Obtenido de https://www.biografiasyvidas.com/biografia/m/mariategui.htm

Bonner, A. (1999). We will not be stopped. Nueva York.

Encyclopaedia Britannica. (s.f.). Encyclopaedia Britannica. Obtenido de https://www.britannica.com/biography/Helder-Pessoa-Camara

Encyclopaedya Britannica. (s.f.). Encyclopaedya Britannica. Obtenido de https://www.britannica.com/biography/Pancho-Villa-Mexican-revolutionary\#ref117904

Fernández de Zamora, R. (2011). Don Juan de Palafox y Mendoza, promotor del libre acceso a la información en el siglo XVII novo- hispano. Centro Universitario de Investigaciones Bibliotecológicas de la UNAM, México.

Fundación Guayasamín (s.f.). Obtenido de http://www.guayasamin.org/index.php/oswaldoguayasamin/biografia

Gutiérrez Escudero, A. (2008). José María Morelos: El siervo de la nación mexicana. Revista Iberoamericana de Filosofía, Política y Humanidades, 235-247.

Hernández Vicencio, T. (2012). Sergio Méndez Arceo y su visión internacionalista. Política y cultura.

Historia de la procuraduría general del Estado. (s.f.). En El procurador general. Dr. Alfredo Pérez Guerrero (junio 1944- marzo 1946) (págs. 71-77).

Instituto Nacional de Solidaridad. (1993). www.Lospobresdelatierra.org. Obtenido de http://lospobresdelatierra.org/textos/biografiacurahidalgo.html

Krieger, P. (2004). La deconstrucción de Jacques Derrida. Anales del Instituto de Investigaciones Estéticas. 
La Estrella de Panamá. (15 de 11 de 2015). La Sinfonía Inconclusa de Schubert.

Martínez Torrejón, J. (s.f.). Biblioteca Virtual Miguel de Cervantes. Obtenido de http://www.cervantesvirtual.com/portales/bartolome_de_las_casas/apunte_biobibliografic $\mathrm{o} /$

Mata, S. (2015). Monseñor Óscar Romero. Pasión por la iglesia. Madrid: Ediciones Palabra.

Morales, J. (2012). Breve historia del Concilio Vaticano II. Madrid: Ediciones Rialp.

Navarro, J. (2007). Contribuciones a la historia del arte en el Ecuador. Quito: Trama Ediciones.

Palou, F. (2002). Junípero Serra y las misiones de California.

Pontificia Universidad Católica del Perú. (2004). Gustavo Gutiérrez. Profesor emérito del Departamento Académico de Teología. En Cuadernos del Archivo de la Universidad. Lima.

Real Academia Española. (2017). Diccionario de la Real Academia Española. Obtenido de http://www.rae.es/

Van Hensbergen, G. (2003). Gaudi: A biography.

Vázquez Carballo, J. (2008). Trinidad y Sociedad. Implicaciones éticas y sociales en el pensamiento trinitario de Leonardo Boff. Salamanca: Secretariado Trinitario. 


\section{Anexo 1 \\ Entrevistas calificadas}

\section{Edgar Velasco López}

\section{Exjesuita, académico y Secretario General de la Universidad Internacional del Ecuador, Quito}

1. ¿Cree usted que la Teoría de la Liberación es un tema vigente o ya es obsoleto? La Teoría de la Liberación es un tema vigente desde que nace la nueva estructura de la Iglesia Católica. Antes la iglesia encerrada en sus colegios o universidades no trascendía, su trabajo no llegaba hacia los más necesitados tal como habla el evangelio. Esta nueva visión teológica, planteaba un cambio profundo para que la gente no vaya a la iglesia sino la iglesia vaya a la gente; esta nueva visión siempre perdurará y siempre estará vigente y siempre será la lucha de muchos que quieren un cambio radical.

2. ¿Qué personaje destacaría para ejemplificar acciones derivadas de la Teoría de la Liberación?

Leonidas Proaño hizo una magnífica obra en Guamote, era el obispo de los indígenas, un hombre que transformó un mundo explotado y logró una liberación en muchísimas comunidades. Si no era por Leonidas Proaño difícilmente la jerarquía hubiese accedido a los cambios tan profundos que se hicieron como La Pastoral donde los indígenas llegaron a formarse teológicamente.

3. ¿Qué nos puede contar sobre los jesuitas asesinados de El Salvador?

Fue un grupo de 6 jesuitas, 4 de ellos fueron mis compañeros. Vinieron a estudiar en Ecuador filosofía y a hacer su Juniorado, se empaparon de toda la problemática latinoamericana, hicieron trabajo social en la universidad, entre muchas actividades importantes en beneficio de la comunidad. Lamentablemente el ejército y el Estado salvadoreño vieron sus acciones positivas y les pusieron muchos límites; de manera atroz una noche llegaron tres pelotones de militares armados, mis compañeros llegaron de trabajar y en su casa descansando les sorprendieron, les sacaron y les dispararon. Defender por la fe y morir en manos de unos asesinos tras lo cual nunca se hizo justicia, esa sangre sirve para los que seguimos en pie y luchamos por el verdadero trabajo. El Estado quería simplemente guardar el estatus, no ver más allá de lo que les convenga, cuidar sus intereses, hablar simplemente de la pobreza y el interés en los más necesitados, pero no llevar esto a la práctica.

La labor de los jesuitas siempre ha sido cuestionada; sin embargo, su misión es "darse a los demás, trabajar para los demás, estar en función y servicio para los demás”. El cuestionamiento existía porque siempre que se habla de liberación y trabajo para los pobres se cree que se habla del comunismo que va en contra de intereses políticos. 


\section{Richard Salazar Medina}

\section{Catedrático universitario, antropólogo, politólogo. Autor de libros y trabajos sobre ritos marianos desde perspectivas de las Ciencias Sociales}

1. ¿Qué rasgos importantes encuentra en Fray Junípero Serra? (Junípero Serra fundó misiones franciscanas desde Querétaro, Baja California y California); tal vez usted pueda dar alguna opinión después de haber visitado California en ámbitos académicos?

En California, Estados Unidos, se respira un ambiente muy latino. Dada mi formación e intereses intelectuales, trato siempre de conocer las plazas centrales de los pueblos o ciudades que visito, por pequeñas o grandes que sean las poblaciones. Lo propio hice en Los Ángeles, donde busqué específicamente la plaza de fundación española de la ciudad. Me llevé una gran sorpresa, puesto que, pese a estar en una ciudad tan moderna como L.A., es una pequeñísima plaza tradicional, que podría ser la de cualquier pueblito mexicano o latinoamericanos, en medio del frenesí de una moderna y enorme ciudad; y lo es, reitero, pese a ello, porque está en un pequeño triángulo en medio de grandes avenidas y semáforos, no muy lejos del downtown de L.A.

Me refiero a esto en vista de que me da la impresión de que existe una fuerte identidad hispana en toda California. Puede parecer una obviedad, pero no deja de llamarme la atención que hayan conservado la placita y una pequeña iglesia, siendo ya ciudad de EEUU y de habla inglesa. Es decir, responde al poder de un estado con lengua ajena al español, más rival del español. Y es que, en toda California, en toda, hay nombres de ciudades, pueblos (Los Ángeles, San Diego, San Francisco, San José, El Gato, etc, etc.) y, dentro de ellas, calles, incluso en los nuevos pueblitos que siguen surgiendo hacia el este de L.A., ya en camino hacia Nevada (Las Vegas), todos sus nombres son en español y de personajes históricos hispanos (Sepúlveda, etc.). Me refiero a esto más como una curiosidad y como una pregunta: ¿Tendrá algo que ver el legado del fraile Junípero Serra en esta fuerte identidad que es respetada por los arios angloparlantes del establishment estadounidense? He visto que ha fundado varias parroquias, misiones, etc. No sé si sea una hipótesis descabellada, pero es lo único que se me ocurre decir.

De hecho, siempre me ha llamado la atención esta nomenclatura en español y que los norteamericanos la usan, orgullosamente, además, porque California es un estado particular en todo sentido y muy de vanguardia. No creo que se deba al hecho de que hay muchos mexicanos ahí, porque el poder ha estado y sigue estando, en el poder de los arios angloparlantes. De hecho, ha sido más fácil que llegue a ser gobernador de este estado un alemán, nacionalizado estadounidense (Arnold Schwarzenegger), que un chicano.

2. ¿Qué de simbólico encuentra en el Concilio Vaticano II, en el Documento de Medellín, Colombia de 1968, y en la III Conferencia General del Episcopado Latinoamericano Puebla en México, 1979?

Tratando de responder principalmente desde lo que puedo decir del Concilio Vaticano II, que es el que conozco. Los otros dos documentos no los conozco. No obstante, todas las fuentes mencionan que la Teología de la Liberación proviene del Concilio Vaticano II (1962 a 1965) y a 
su derivación de la Carta Encíclica Populorum Progressio que me parece que es de 1967. Y es que más que nada en esto veo un cambio simbólico importante en la Iglesia, que puede manifestarse de la siguiente manera: desde mi propia perspectiva, es la primera vez que la iglesia asume un rol transitivo de la evangelización; es decir, hasta ese momento era como que se dijera "yo te evangelizo a ti, ser sin religión, ser ignorante e incluso ignorado (aunque se lo dijera con piedad), te transfiero, te entrego, te doy la palabra de Dios, para que superes ese estado 'natural'...". Reitero, siendo una acción transitiva, de la Iglesia y sus sacerdotes, a los sujetos evangelizados, que es como si se les diera un regalo, se le entregara un Dios, asumiendo que antes no lo tenía. Puede que los teólogos hagan pedazos mis argumentos, que yo esté diciendo algo para ellos impropio o falso, pero es lo que me parece.

A partir de las preocupaciones del Concilio Vaticano II, la Encíclica Populorum Progressio hace mucho énfasis en que la Iglesia trabajará para la gente, para su pueblo, para los más pobres. Es entonces ya no una acción transitiva y asistencial, paternal, sino que es ponerse al servicio de los desprotegidos, de los menos afortunados, personas, pueblos, países y regiones, para lograr su desarrollo y la superación de la pobreza, para hacer que el bienestar del desarrollo científico y de las sociedades modernas, llegue a todos; todo lo cual forma los postulados fundamentales de la Teología de la Liberación.

No es casualidad que, tanto en la encíclica, como en la Teología de la Liberación, se habla no solo de servicio, sino también de renta, de capitalismo, de desarrollo, de planificación, de pobreza, de alfabetización, de promoción cultural, de pluralismo, de solidaridad, etc. Es decir, es evidente que en su contenido encontramos postulados y conceptos definitivamente ligados a las Ciencias Humanas, incluida la Economía Política, marxista, por cierto, e incluso postulados de la segunda generación de los Derechos Humanos: los Derechos Económicos, Sociales y Culturales, que además coinciden en el tiempo, ya que fueron postulados justamente en la segunda mitad de la década de 1960 (1966 la mayoría). Creo, entonces, que la Teología de la Liberación y el propio Concilio Vaticano II respondieron a una necesidad histórica de actualización de la Iglesia con la realidad de los tiempos y los espacios en donde actúan. Sin embargo, tengo la certeza de que hubo una enorme resistencia a estas tendencias en el statu quo de la Iglesia Católica y de los propios gobiernos latinoamericanos, ya que, como tiene una raigambre netamente social (para no decir socialista que tendría otra connotación que merece mucho más reflexión y en este momento se presta a interpretaciones antojadizas, muy tergiversadoras), incluso marxista, esto provocó una reacción furibunda de los gobiernos más conservadores, latinoamericanos y estadounidenses, y sus dictaduras, que llevaron a asesinatos de sacerdotes en varios países (El Salvador, Guatemala, Bolivia, etc.) y, en Centroamérica especialmente, de muchas poblaciones de indígenas y campesinos, ya reconocidas, pero no por ello menos lastimosas; de allí precisamente el Premio Nobel de Rigoberta Menchú.

Me parece que la Teología de la Liberación fue una tendencia necesaria y que ha dejado una huella positiva luego de las dolorosas experiencias y luchas que le tocó afrontar en América Latina. He visto sacerdotes que han tratado de hacer una labor en ese sentido. De parte de Populorum Progressio, no hay que olvidar que en el Ecuador hay una labor muy paradigmática, ya que precisamente con ese mismo nombre, se creó una organización no gubernamental que ha crecido de manera enormemente significativa y que al presente es un emporio de trabajo en 
temas de desarrollo local: el Fondo Ecuatoriano Populorum Progressio (FEPP), que ahora tiene hasta un banco propio: Codesarrollo, que ha hecho una labor enorme en temas de micro finanzas.

No obstante, ello, me parece que tanto la Teología de la Liberación como la Encíclica del Populorum Progressio y el Concilio Vaticano II ya tuvieron su tiempo. Me parece que la Iglesia en este momento para actuar con responsabilidad debe empezar a tratar con seriedad y profundidad en tema del voto de castidad, entre otras cosas. No puede ser que permanentemente estemos acostumbrados ya a enterarnos de escándalos de pederastia, violaciones y de situaciones anómalas, que además finalmente no pasan de ser escándalo, ya que hay protección de la propia Iglesia, con un incomprensible espíritu de cuerpo. De igual forma, otros escándalos de corrupción que son plenamente comparables a las tramas más oscuras de casos como el de Odebretch, pero en el Vaticano, a nivel global. Digo todo esto desde una perspectiva laica, no soy católico ni profeso ninguna religión, pero es innegable la influencia que tiene el catolicismo en el mundo, particularmente en América Latina, por lo cual es menester afrontar estas temáticas.

\section{Su opinión sobre Monseñor Luna Tobar}

Tuve la oportunidad de saludar con él en unas pocas ocasiones que coincidimos en reuniones, es decir, no fui su amigo ni conocido. No obstante, conozco su obra especialmente por medio de la Fundación Donum de Cuenca, con la cual si pude trabajar en un par de proyectos en los años 2000 y 2001. Esta fundación fue iniciativa propia de Luna Tobar y puedo dar testimonio que su trabajo, absolutamente laico, con personal de primera, profesionales comprometidos de todo el país, hacían y seguramente siguen haciéndolo, una labor en las zonas más alejadas de varias provincias, allá donde el Estado y las campañas políticas nunca llegaban. Creo que Luna Tobar es un ejemplo de la manera más inteligente de no solo decir, sino de hacer, más allá de que nunca calló ante la injusticia ni ante lo incorrecto en el seno de su trabajo, ni en la política nacional.

\section{Bolívar Chiriboga Valdivieso}

\section{Académico, abogado, vicepresidente de la Fundación Ecuador- observatorio de políticas públicas, ex candidato a la presidencia de la República por el Partido Liberal}

1. ¿Cuál es la importancia del laicismo como principio ligado a la libertad de cultos?

Después de la vida, la libertad es el mayor de los dones y valores de una persona y una sociedad. Como consecuencia de esto, la libertad sea política o religiosa es muy importante, cada persona tiene derecho a escoger su camino.

La vida por sí sola no tiene sentido si no eres libre; sin embargo, la libertad de una persona termina cuando empieza la libertad de otra persona. Ese es un principio fundamental. Como todos los valores, tiene sus limitaciones, y comenzado por la vida tiene una monstruosa limitación: la enfermedad y la muerte. Yo no puedo pasarme de la línea que separa mis derechos para agredir los derechos fundamentales de otras personas. 
2. ¿Cómo mira usted el papel ejercido por el clero en las Américas?

Ha habido etapas positivas y negativas; las negativas son aquellas en donde se imponían las ideas sin restricción alguna a los demás, y penosamente con mayor intensidad a los más pobres de nuestros países y de otros países más civilizados.

En la etapa actual su papel es ponderado y adecuado sin dejar de mencionar abusos específicos de ciertos clérigos, pero ya no de una iglesia como todo sino de ciertos miembros negativos de esa iglesia.

3. Su comentario sobre obispos que han impulsado la Teología de la Liberación en América

Hay un personaje que fue un estandarte de la teoría de la liberación que nació en Imbabura, pero ejerció en Riobamba, se trata de Leónidas Proaño. Él es el mejor ejemplo del ejercicio de la tesis de la teoría de liberación que le permitió luchar en favor de los más pobres, logró darles una esperanza de vida que hasta ahora les ha sido beneficioso y positivo. 